\title{
Effects of the laser cutting parameters on the micro-hardness and on the heat affected zone of the mi-hardened steel
}

\author{
M. Boujelbene ${ }^{1,2, *}$, A. S. Alghamdi ${ }^{1}$, I. Miraoui ${ }^{3}$, E. Bayraktar ${ }^{4}$, M. Gazbar ${ }^{2}$ \\ ${ }^{1}$ College of Engineering, University of Hail, Hail, Saudi Arabia \\ ${ }^{2}$ ME Laboratory, ENIT, Ecole Nationale d'Ingénieurs de Tunis, University of Tunis El Manar, Tunis, Tunisia \\ ${ }_{3}$ MEER, Laboratory, College of Sciences, University of Gafsa, Gafsa, Tunisia \\ ${ }^{4}$ SUPMECA/LISMMA-Paris, School of Mechanical and Manufacturing Engineering, Paris, France
}

\section{A R T I C L E IN F O}

\section{Article history:}

Received 9 January 2017

Received in revised form

23 March 2017

Accepted 5 April 2017

\section{Keywords:}

Laser cutting

Cutting speed

Laser power

Heat affected zone

Microhardness

\begin{abstract}
A B S T R A C T
High power $\mathrm{CO}_{2}$ laser cutting of $6 \mathrm{~mm}$ thick $\mathrm{C} 45$ steel sheets is investigated with the aim of evaluating the effect of the various laser cutting parameters such as laser power and cutting speed, on the laser cutting quality. In this study, cutting quality was evaluated by measuring the thickness of the Heat Affected Zone (HAZ), the microhardness beneath the cut surface (HV) and the cut section roughness. A simple and practical model was proposed to predict the thickness of the HAZ and the microhardness as a function of two, namely parameters; laser power and cutting speed. The adequacy of the proposed models was tested by analysis of variance (ANOVA). The Experimental data were compared with modelling data to verify the capability of the proposed model. The results indicate that laser power and cutting speed are determinant cutting-parameters on the HAZ thickness and microhardness beneath the cut section.
\end{abstract}

(C) 2017 The Authors. Published by IASE. This is an open access article under the CC BY-NC-ND license (http://creativecommons.org/licenses/by-nc-nd/4.0/).

\section{Introduction}

Laser processing of sheet metals has a wide scope of applications in industry. The high energy focused laser beam provides a fast processing and an excellent precision of the operation. Since the laser processing involves high temperatures gradient depended mainly on laser power, cutting speed, laser beam diameter, pulse frequency and focus position. This, in turn, causes a generation of thermal stress in the irradiated region. In addition, the high cooling rates contribute to the stress formation in this region.

Laser beam cutting is an advantageous technology, which allows the reduction of total work times, the increase in production quality added to the simplicity of the operation and a high degree of automation and flexibility. Several investigations have confirmed this process as a very reliable technology. Polypropylene PP, polycarbonate PC, many polymeric, metallic and non-metallic materials are cut by different types of lasers at different operation modes, different gas jet, different powers

\footnotetext{
* Corresponding Author.

Email Address: mboujelbene@yahoo.fr (M. Boujelbene) https://doi.org/10.21833/ijaas.2017.05.003

2313-626X/C 2017 The Authors. Published by IASE.

This is an open access article under the CC BY-NC-ND license

(http://creativecommons.org/licenses/by-nc-nd/4.0/)
}

and of course different laser beam diameter (Eltawahni et al., 2012; Singh and Gary, 2009; Yilbas et al., 2010; Jebbari et al., 2008; Dubey and Yadava, 2008; Ghany and Newishy, 2005; Benyounis et al., 2008; Miraoui et al., 2016).

Laser cutting of metallic materials is extensively used as an efficient manufacturing process in industrial applications; automotive, chemical industry, aeronautical and aerospace field. However, internal thermal stresses are developed in the region of the cutting section of the pieces. Depending on the cutting parameters and the substrate material properties, the thermal stress levels can reach very high values and therefore, can influence the microstructure of the cutting surface (Miraoui et al., $2013,2015)$. Due to the heat treatment introduced by the already mentioned high thermal gradient in the substrate material, a very sensitive white layer (WL) on the cutting surface is observed and a heavily changed zone called Heat Affected Zone (HAZ) is occurred just under it. This phenomenon can easily cause damage in that area of the pieces under service conditions (M'Hamdi et al., 2013). Alloy laser cutting is more advantageous than conventional methods; we can mention that it's considered as a non-contact cutting-process which means a zero tool wearing, we can also profit from a local treatment coupled with a good precision and a low cost. The presence of certain alloying elements in the matrix alters the 
thermal resistance of the materials during laser machining (Singh and Gary, 2009; Yilbas et al., 2010; Jebbari et al., 2008; Benyounis et al., 2008; Dubey and Yadava, 2008; Shanjin and Yang, 2006). Extensive research studies were carried out to examine laser processing of metallic alloys (Yilbas, 2008; Yilbas et al., 2012, Benyounis et al., 2008). They indicated that this technique is much better than other conventional cutting techniques. Jebbari et al. (2008) conducted an extensive study to evaluate the HAZ especially on the C42 steel (Miraoui et al., 2016). Benyoynis et al. (2008) treated a similar study on HAZ and/or structural changed area for different thermoplastic materials. A comparative study on HAZ, made by Olabi et al. (2007), gave many results similar to those of Yilbas et al. (2012). However, a detailed study on the HAZ depending on test conditions was carried out by Yilbas et al. (2010). They focused especially on materials parameters (composition and thickness, etc.) and operational parameters such as welding speed. They showed experimentally that a higher welding speed always decreases the length size of HAZ considerably, and reduces the surface defects. Miraoui et al. (2013) studied and optimized the effect of $\mathrm{CO}_{2}$ laser cutting on the cut surface characteristics such as the surface roughness of low carbon steel. An adequate precision ratio above 4 indicates that the model is adequate (Olabi et al., 2007; Eltawahni et al., 2012). An adequate model means that the reduced model has successfully passed all the required statistical tests and can be used to predict the responses or to optimize the process. Boujelbene et al. (2009) made a study of the influence of machining parameters (micro-hardness, HAZ, White Layer Thickness WLT) on the surface integrity in electrical discharge machining of the X200Cr15 and 50CrV4 steel for dies and moulds and dies castings.

Uslan (2005) found that increasing the laser power intensity enhances the kerf width size and this is more pronounced with reducing cutting speed. It was reported that a small variation in laser power results in a large variation in the kerfs size. He reported that the influence of cutting speed was less than that corresponding to the laser power.

In the present study, white Layer and HAZ developed in the region of the laser cut edges are evaluated and a parametric approach model is used to predict these phenomena due to the variation of the maximum temperature on the surface along the moving direction of the laser heating source with a constant speed along the cut edge. This situation lowers the process quality. Therefore, a comprehensive study becomes essential for the predictions of microhardness and thickness of the HAZ and surface topography which are validated through the experimental results.

\section{Experimental procedure}

Laser cutting operations for testing requirements were performed on simple carbon steel type C45.
Small samples were cut by laser to prepare $6 \mathrm{~mm}$ thick test specimens taken from the sheet parts. Chemical composition of this steel structure is given in Table 1 and mechanical properties are indicated in Table 2.

Table 1: Chemical composition of C45 steel

\begin{tabular}{cc} 
Fe \% & 98 \\
$\mathrm{Mn} \%$ & $\sim 0.5$ \\
$\mathrm{C} \%$ & $\sim 0.45$ \\
$\mathrm{Si} \%$ & 0.4 \\
$\mathrm{Mo} \%$ & 0.1 \\
\hline
\end{tabular}

Table 2: Basic mechanical properties of C45 steel $\begin{array}{cc}\text { UTS (MPa) } & 730 \\ \sigma_{\mathrm{y}}(\mathrm{MPa}) & 410 \\ \mathrm{~A}(\%) & 17\end{array}$

For the Laser cutting operations, a laser cutting machine Type AMADA AS $4000 \mathrm{E} / \mathrm{CO}_{2}$ was used for the cutting of the specimens.

Cutting operations were conducted with the following conditions:

- Cutting speeds applied (Vf): 560; 1400 and 2240 $\mathrm{mm} / \mathrm{min}$.

- Laser power applied (Pu): 3; 4 and 5 KW.

Microhardness and metallographic tests $\left(\mathrm{HV}_{\mathbf{0}, \mathbf{1}}\right)$ were made on the specimens (mounted and polished and etched) to evaluate the hardness evolution from the cutting surface to the center of the specimens. Microstructural evolution near the cutting surface was made with an optical microscope. Detailed analysis of the evolution in the microstructure, such as the thickness of HAZ, hardening or softening under the cut surface and other surface details were carried out by Scanning Electron Microscope.

The results from twelve specimens were used for statistical analysis (ANOVA), and also of the validation of the proposed mathematical models as a function of basic testing variables; Laser power and cutting speed.

\section{Results and discussions}

\subsection{Evaluation of HAZ after laser cutting}

The morphology of the surface that has undergone Laser Cutting is affected by both the enormous amount of heat generated by the discharges, which causes melting and vaporization of the material and the rapid cooling that follows. Generally, a typical structural evolution is observed just below the cut surface due to very fast heat treatment during the cutting operation. This zone is called HAZ. Very often, a White Layer (WL) is formed in this zone and is difficult to make a difference between WL and HAZ because of the heavily heat treatment that occurs in this area.

Laser cutting $\left(\mathrm{CO}_{2}\right)$ of sheet metal is an economically feasible method of production through advances in technology. It uses a computer controlled high-power laser, and causes the material 
to melt burn, vaporize away, or blow away by a jet of gas leaving an edge with a high-quality surface finish. Laser cutting operations generally produce regular patterns in the cut surface, known as striations. The frequency and amplitude of these striations has a direct impact on surface quality.

The evolution of the HAZ indicates a heavily changed zone under the cut surfaces. An Optical microscope was used to characterize the evolution of the HAZ, and to measure its thickness values (Fig. 1).

Table 3 gives the measurements of the thickness values of the HAZ just below the cut surfaces for C45 steel as a function of the cutting parameters; cutting speed $V_{f}$ and power $P_{u}$. These values will be used with validation of the parametric model in the next section.

The thickness values shown in the Table 3 are the mean values of 3-5 measurements obtained from different locations of the same specimens.

\subsection{Evaluation of microhardness developed in HAZ after Laser cutting}

Experimental results for microhardness measurements obtained for the $\mathrm{C} 45$ steel are given in Table 4. Once more, for this analysis, the mean microhardness values taken from 3 measurements of different location for each specimen were classified as a function of cutting speed and power. All the measurements were made at two distances from the cut surface; $\mathrm{D}=10 \mu \mathrm{m}$ and $\mathrm{D}=210 \mu \mathrm{m}$ as indicated in Table 4.

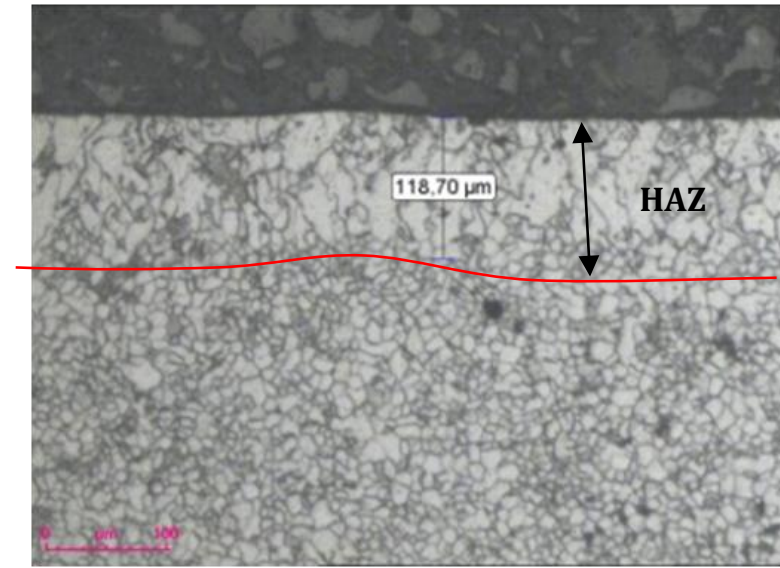

Fig. 1: Evolution of HAZ below the Laser cut surfaces $\left(\mathrm{V}_{\mathrm{f}}=\right.$ $2240 \mathrm{~mm} / \mathrm{min}$ and $\mathrm{P}_{\mathrm{u}}=3000 \mathrm{~W}$ )

Table 3: Evolution of HAZ just below the Laser cut surfaces for different test conditions

\begin{tabular}{cccc}
\hline $\begin{array}{c}\mathrm{N} \text { of } \\
\text { Variables }\end{array}$ & $\begin{array}{c}\text { Cutting speed, } \\
\mathrm{V}_{\mathrm{f}}(\mathrm{mm} / \mathrm{min})\end{array}$ & $\begin{array}{c}\text { Power, } \\
(\mathrm{W})\end{array}$ & $\begin{array}{c}\mathrm{HAZ} \\
(\mu \mathrm{m})\end{array}$ \\
\hline 1 & 560 & 3000 & 164,52 \\
2 & 2240 & 3000 & 126,06 \\
3 & 560 & 5000 & 231,63 \\
4 & 2240 & 5000 & 143,01 \\
\hline
\end{tabular}

\subsection{Parametric approach model: Statistical analysis (ANOVA method)}

Parametric approach model is a powerful analysis tool for modelling and analysing the influence of process variables on a specific variable, which is an unknown function of this process variable (Scintilla and Tricarico 2012; Miraoui et al. 2013, 2016).

Table 4: Microhardness values (mean) as a function of cutting parameters

\begin{tabular}{ccccc}
\hline Test No. & Cutting speed, $\mathrm{V}_{\mathrm{f}}(\mathrm{mm} / \mathrm{min})$ & Power, $\mathrm{P}_{\mathrm{u}}(\mathrm{W})$ & Distance from cut surface, $\mathrm{D}(\mu \mathrm{m})$ & Microhardness $\left(\mathrm{HV}_{0,1}\right)$ \\
\hline 1 & 560 & 3000 & 10 & 136 \\
2 & 2240 & 3000 & 10 & 131 \\
3 & 560 & 5000 & 10 & 154 \\
4 & 2240 & 5000 & 10 & 145 \\
5 & 560 & 3000 & 210 & 131,5 \\
6 & 2240 & 3000 & 210 & 119,3 \\
7 & 560 & 5000 & 210 & 138,3 \\
8 & 2240 & 5000 & 210 & 128 \\
\hline
\end{tabular}

Analysis of variance (ANOVA) is process parameters, which considerably affect to the size of the HAZ and microhardness, are obtained through ANOVA (Uslan, 2005). It is one of the widely used techniques by the researchers for the interpretation of experimental works.

ANOVA is not a complicated method and has a lot of mathematical beauty associated with it. It is a technique that partitions the total sum of squares of deviations of the observations about their mean into portions associated with independent variables in the experiment and a portion associated with error. It is a statistically based, objective decision-making tool for detecting any difference in average performance or group of items tested. The decision, rather than using pure judgment, takes variation into account. It is a mathematical technique which breaks total variation down into the account table sources; total variation is decomposed into appropriate components. Here in ANOVA, we have considered the effect of one controlled parameter upon the performance of the process.

In general, after Laser cutting, the HAZ and the microhardness (HV) parameters mainly depend on the manufacturing conditions mentioned above. Thus, a complete modelling of these parameters (HAZ and microhardness) should take into account all the previous factors for modelling.

In the frame of the present work, a statistical analysis (ANOVA) has been carried out for the prediction of all of the HAZ and microhardness evaluations based on the experimental results as discussed in the former sections. A mathematical model was determined for each steel structure after having recourse to a parametric approach according to ANOVA analysis.

At the first stage, certain criteria were chosen from statistical tables. In the case of this paper (Fig. 
2), "Fisher - Snedecors law" with a probability of 0.05 has been chosen;

Value of the variable $f$ "Fisher-Snedecor" $\mathrm{F}$ $(v 1 ; v 2)$ with the probability of being exceeded 0.05 with;

1: the numerator degrees of freedom

$v 2$ : the denominator degree of freedom

$d_{f}$ : degree of freedom,

SS: Sum of Squares,

MS: Mean Square,

df was taken as follows;

$4=\mathrm{d}_{\mathrm{f}}$ treatment, $1=\mathrm{d}_{\mathrm{f}}$ error

$F$ test: the number found after a Fisher test

$F$ theoretical: the number of Fisher test.

The number of Fisher test can be chosen from statistical analysis from the table according to "Fisher-Snedecors law" with a probability of 0.05 , for HAZ and for microhardness evaluation.

After that, test parameters were taken into account as cutting speed $V_{f}$ and power $P_{u}$, and for the measurement of microhardness, a distance parameter was also considered as D distance from cut surface.

At the final stage, after analyzing results proposed in the Tables 5 and 6, cooling from the statistical treatment made for C45 steel based on experimental design using ANOVA method we can make some deductions and comments:

First of all, by comparing values from Table 5 in order to quantify and to evaluate the effect of cutting speed and cutting power and also the interaction between these two parameters on the thickness of $\mathrm{HAZ}$, after that we may conclude that the interaction of cutting speed $V_{f}$ and power Laser $P_{u}$ is very weak thus this interaction can be neglected in case of C45 steel.

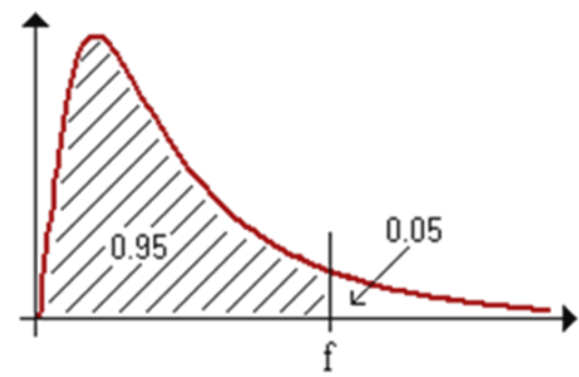

Fig. 2: Fisher-Snedecors' law with a probability of 0.05

A Similar analysis was conducted for the ANOVA treatment for the microhardness (HV) measurements as shown in Table 6, leads us to the conclusion that the interactions between parameters can be neglected.

As presented the results of ANOVA analysis for C45 steel in Tables 5 and 6, the "Ficher" test has shown more influence of the power $P_{u}$ and the distance from cut surface $D$, on the microhardness values. In our case, the influence of the cutting speed $V_{f}$ can also be considered; in fact because the values $F_{\text {test }}$ (the value obtained after a Fisher test) and
$F_{\text {theoretical }}$ (the value of the Fisher test) are very close each other. In addition to that, as mentioned, the interaction between the cutting speed and the cutting power can be neglected.

At the end of the ANOVA analysis, we shall consider the limits of the mathematical model used to predict the evolution of HAZ and microhardness $\mathrm{HV}$ depending on the test parameters taken into account in the frame of the present work.

To design a mathematical model, Taguchi method has been used. After obtaining values from the statistical analysis, the final form of the model proposed here is the following Eq. 1.

$\operatorname{Rep}=\propto \cdot A^{\beta} \cdot B^{\gamma}$

Evidently, the results found according to this model are proposed for C45 steel structures (Eqs. 2 and 3);

Thickness HAZ $=23.939 . \mathrm{Vf}^{-0,27} \cdot \mathrm{Pu}^{0,458}$

Microhardness $=52 \cdot 547 . \mathrm{Vf}^{-0,049} \cdot \mathrm{Pu}^{0,1697} \cdot \mathrm{D}^{-0,0295}$

Table 5: ANOVA results for the measurement of HAZ

\begin{tabular}{ccccccc}
\hline Variables & $\mathrm{d}_{\mathrm{f}}$ & $\mathrm{SS}$ & $\mathrm{MS}$ & $\mathrm{F}_{\text {test }}$ & & $\mathrm{F}_{\text {theoretical }}$ \\
\hline $\mathrm{Vf}$ & 1 & 8075,3 & 8075,3 & 372,8 & $>$ & 7,71 \\
$\mathrm{Pu}$ & 1 & 3533,6 & 3533,6 & 163,1 & $>$ & 7,71 \\
$\mathrm{Vf}, \mathrm{Pu}$ & 1 & 1257,8 & 1257,8 & 8,06 & $>$ & 7,71 \\
Error & 4 & 86,64 & 21,66 & & & \\
Total & 7 & 12953,4 & & & & \\
\hline
\end{tabular}

Table 6: ANOVA results for the Hardness measurement

\begin{tabular}{ccccccc}
\hline Variables & $\mathrm{d}_{\mathrm{f}}$ & $\mathrm{SS}$ & $\mathrm{MS}$ & $\mathrm{F}_{\text {test }}$ & & $\mathrm{F}_{\text {theoretical }}$ \\
\hline $\mathrm{Vf}$ & 1 & 666,12 & 666,12 & 3,89 & $<$ & 5,32 \\
$\mathrm{Pu}$ & 1 & 1128,1 & 1128,1 & 6,58 & $>$ & 5,32 \\
$\mathrm{D}$ & 1 & 1195,6 & 1195,6 & 6,98 & $>$ & 5,32 \\
$\mathrm{Vf}, \mathrm{Pu}$ & 1 & 2,20 & 2,20 & 0,01 & $<$ & 5,32 \\
$\mathrm{Vf}, \mathrm{D}$ & 1 & 36,12 & 36,12 & 0,21 & $<$ & 5,32 \\
$\mathrm{Pu}, \mathrm{D}$ & 1 & 136,12 & 136,12 & 0,79 & $<$ & 5,32 \\
Vf, Pu, D & 1 & 17,40 & 17,40 & 0,10 & $<$ & 5,32 \\
Error & 8 & 1369,8 & 171,22 & & & \\
Total & 13 & 4551,49 & & & & \\
\hline
\end{tabular}

\subsection{Parametric diagrams to predict the evolution of HAZ}

This type of evaluation can be concentrated on the production of parametric diagrams as useful tools to observe and predict the influence of the test parameters on the HAZ and their interactions by using these formula and the results obtained from the analysis discussed just above.

As usual, the interaction diagrams for HAZ can give the parallel action of the test parameters (Fig. 3). From Fig. 3, we can identify the interaction between two basic parameters: cutting speed and laser power. The interaction shows a weak effect for HAZ. For this reason this interaction was neglected.

The same relations can be shown with detailed parametric diagrams constructed for the evolution of the thickness of HAZ (as data- mean value) as a function of cutting speed and laser power (Fig. 4).

Fig. 4 indicates that the thickness of the HAZ is proportional to the laser power and inversely proportional to the cutting speed.More detailed indications are shown in Fig. 5 with 3D parametric 
surface diagrams for the evolution of HAZ depending on the cutting speed and laser power. It supports the results already evoked.

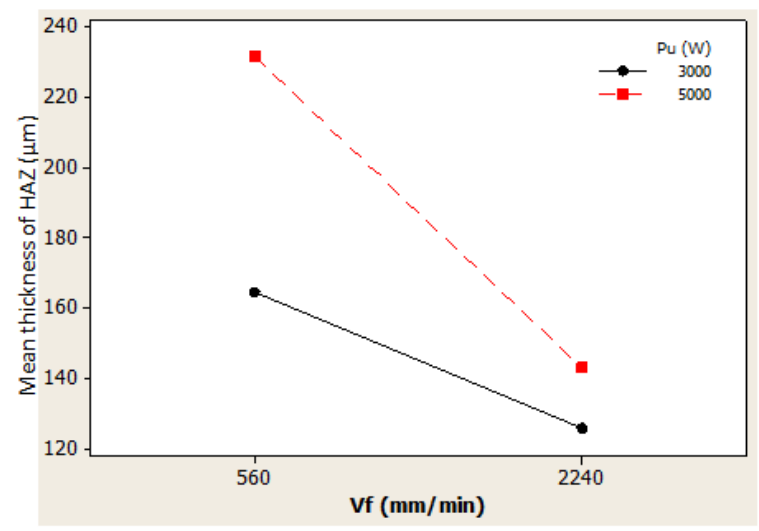

Fig. 3: Interaction diagram for HAZ of two parameters, cutting speed $V_{f}$ and laser power $P_{u}$.

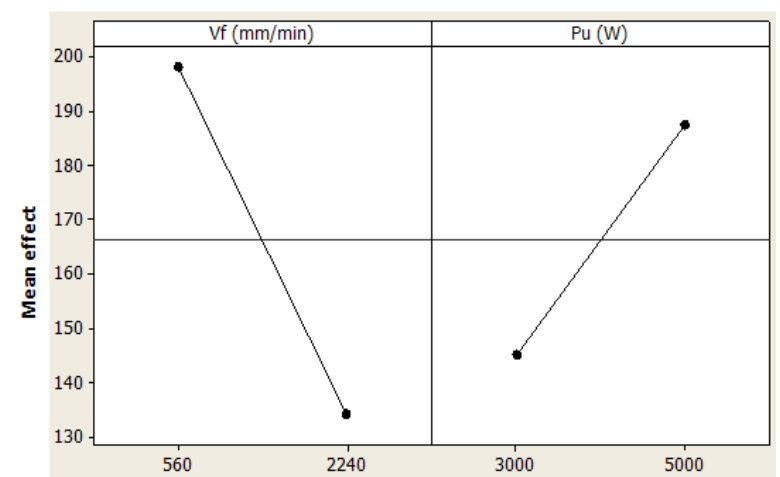

Fig. 4: Mean effect of cutting speed $V_{f}$ and the Laser power $\mathrm{Pu}_{\mathrm{u}}$ on the thickness of the HAZ

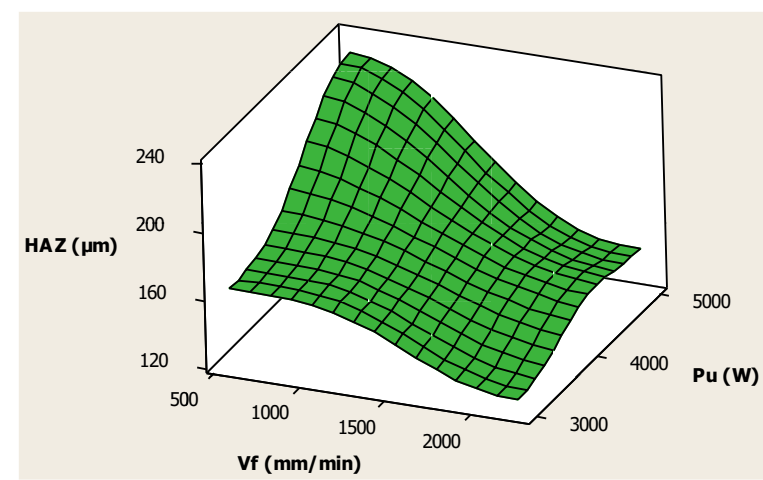

Fig. 5: Surface diagram of HAZ; Effect of cutting speed $V_{f}$ and the Laser power $P_{u}$ on the thickness of the HAZ

More comprehensible 3D parametric diagrams as isocurve responses of the evolution of HAZ depending on the cutting speed and laser power (Fig. 6 ). One may choose the production parameters from these diagrams.

\subsection{Parametric diagrams to predict the evolution of microhardness in HAZ}

Evaluations via parametric diagrams have also been carried out to predict the influence of the test parameters on the microhardness developed in HAZ and to observe the interactions of the test parameters as discussed just in the former section.
In a practical way, we may conclude from Figs. 7, 8 , and 9 that the interaction of test parameters for the evolution of microhardness can be neglected.

And similarly, Fig. 10 gives mean effect of cutting speed $V_{f}$ and the Laser power $P_{u}$ and the distance from cut surface $D$ on the evolution of microhardness for C45 steel.

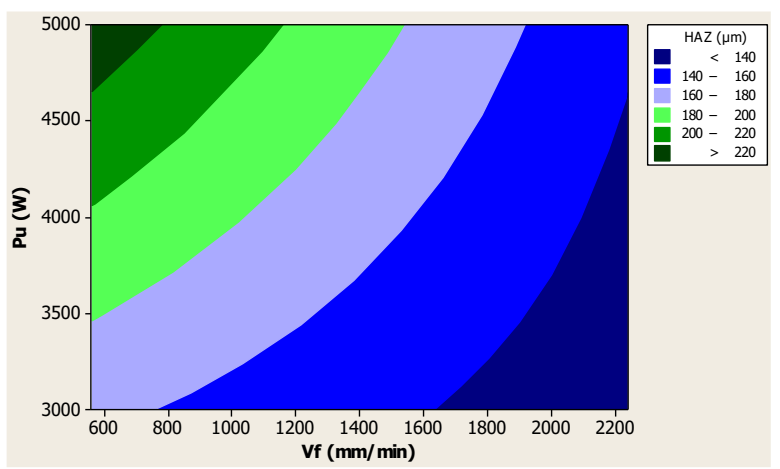

Fig. 6: Isocurve response of the HAZ as a function of the cutting speed $V_{f}$ and the Laser power $P_{u}$

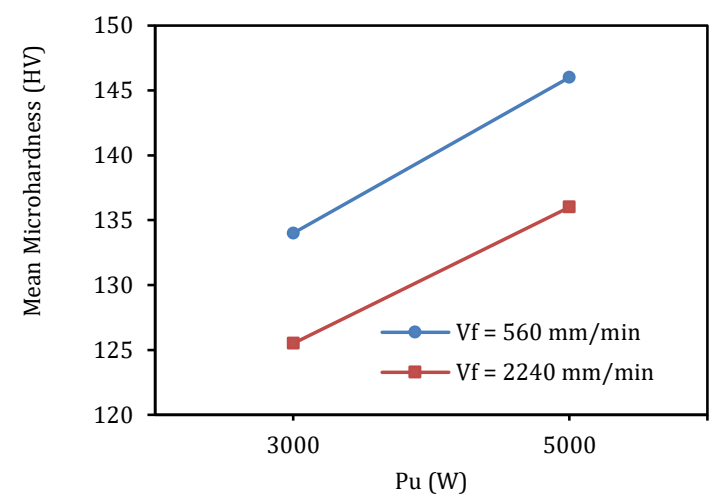

Fig. 7: Interaction for microhardness evolution between cutting speed $V_{f}$ and the Laser power $P_{u}$

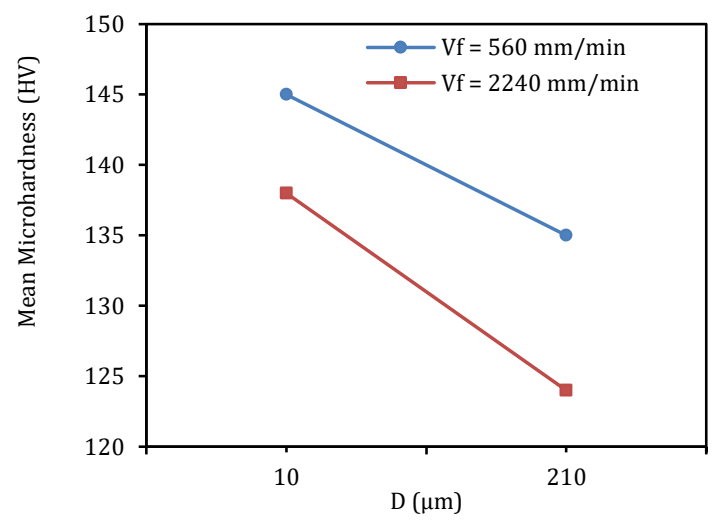

Fig. 8: Interaction for microhardness evolution between cutting speed $V_{f}$ and the distance from cut surface $D$

Fig. 11 presents 3D-Surface diagrams that give more details for the effect of cutting speed $V_{f}$ and the laser power $P_{u}$ on the evolution microhardnes in HAZ.

Fig. 12 gives isocurve responses of the microhardness (HV) depending on the cutting speed and the laser power for the C45 steel. They show that evolution of microhardness is proportional with power. However, the cutting speed and the microhardness evolution are inversely proportional. 


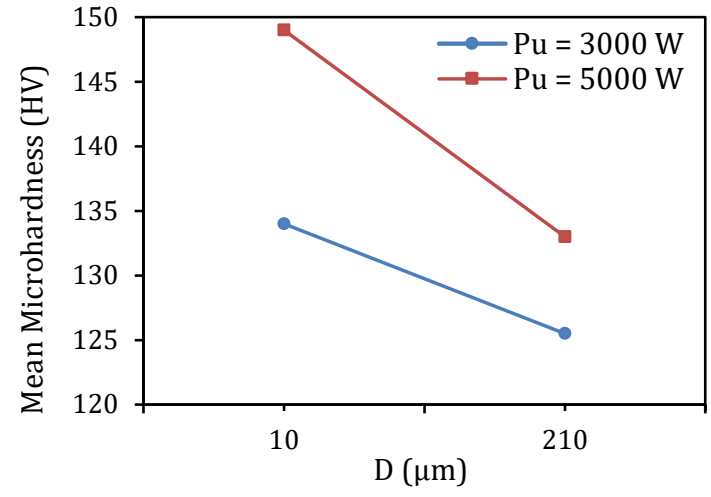

Fig. 9: Interaction for microhardness evolution between power $\mathrm{P}_{\mathrm{u}}$ and the distance from cut surface $D$

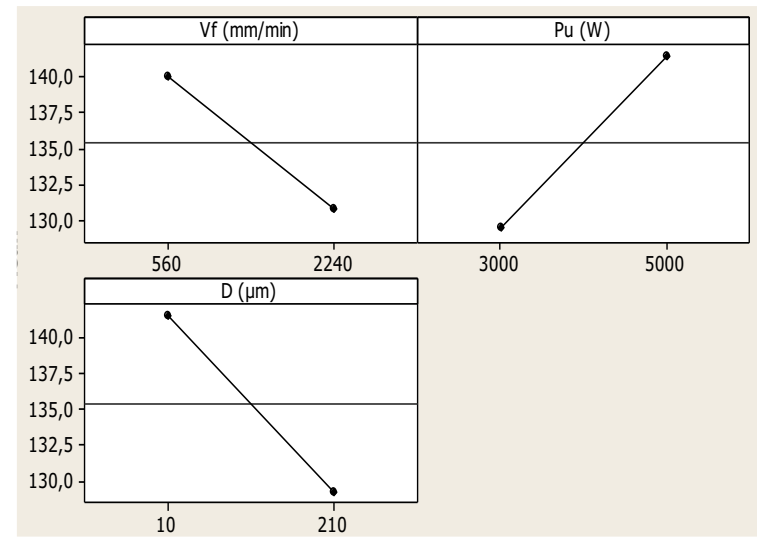

Fig. 10: Mean effect of cutting speed $V_{f}$ and the Laser power $P_{u}$ and the distance from cut surface Don the microhardness occurred in HAZ

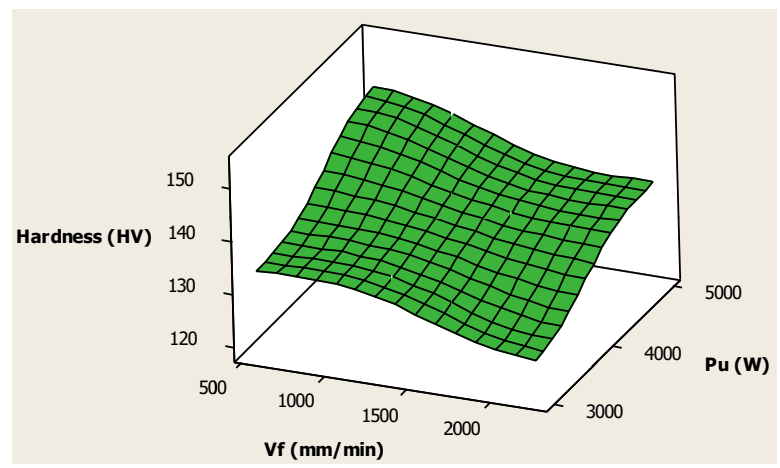

Fig. 11: Effect of cutting speed $V_{f}$ and the Laser power $P_{u}$ on the microhardness in HAZ

\section{Conclusion}

In present work analyses, the microstructure damage such as HAZ after the laser cutting operations in different test conditions and proposes a parametric approach model via ANOVA. This models to predict the thickness of HAZ and also to predict the microhardness (HV) evolution in HAZ depending on the different experimental test conditions by the means of a simple mathematical model considered as a practical tool.

We can reason out that cutting speed $V_{f}$ and Laser power $P_{u}$ used here are determinant cuttingparameters on the thickness of HAZ area and the evolution of microhardness.
The thickness of HAZ decreases as the cutting speed increases and it increases as the laser power increases.

The microhardness beneath the cut surface increases as the laser power increases and decreases as the cutting speed increases.

The increasing of laser cutting speed can significantly improve the surface quality of the cutting parts of the $\mathrm{C} 45$ steel.

The proposed models may be considered as valid ones and they can be used to predict the machining responses under the experimental conditions.

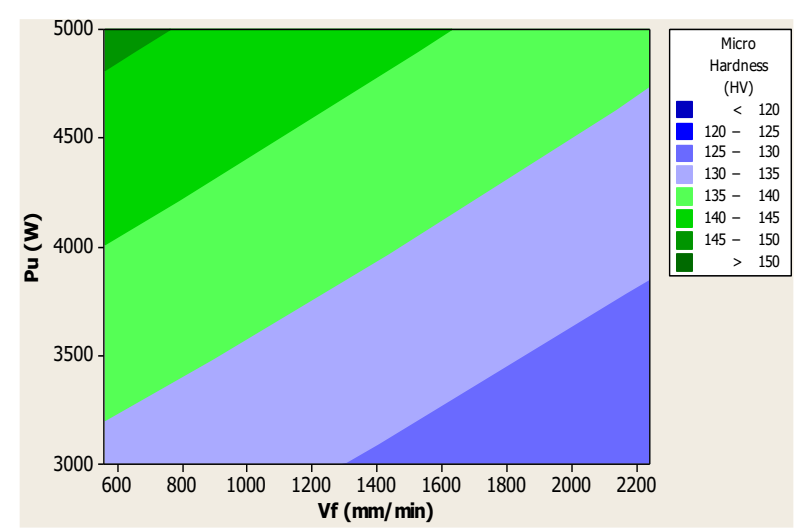

Fig. 12: Isocurve response of the microhardness (HV) as a function of the cutting speed $V_{f}$ and the Laser power $P_{u}$

\section{Acknowledgement}

The authors would like to thank the Deanship of the Scientific Research of University of Hail, Kingdom of Saudi Arabia, KSA, for funding and supporting this research project (0150397).

\section{References}

Benyounis KY, Olabi AG, and Hashmi MSJ (2008). Multi-response optimization of $\mathrm{CO}_{2}$ laser welding process of austenitic stainless steel. Optics and Laser Technology, 40(1): 76-87.

Boujelbene M, Bayraktar E, Tebni W, and Salem SB (2009). Influence of machining parameters on the surface integrity in electrical discharge machining. Archives of Materials Science and Engineering, 37(2): 110-116.

Dubey AK and Yadava V (2008). Multi-objective optimization of laser beam cutting process. Optics and Laser Technology, 40(3): 562-570.

Eltawahni HA, Hagino M, Benyounis KY, Inoue T, and Olabi AG (2012). Effect of $\mathrm{CO}_{2}$ laser cutting process parameters on edge quality and operating cost of AISI 316L. Optics and Laser Technology, 44(4): 1068-1082.

Ghany KA and Newishy M (2005). Cutting of $1.2 \mathrm{~mm}$ thick austenitic stainless steel sheet using pulsed and CW Nd: YAG laser. Journal of Material Processing Technology, 168(3): 438447.

Jebbari N, Jebari MM, Saadallah F, Tarrats-Saugnac A, Bennaceur $\mathrm{R}$, and Longuemard JP (2008). Thermal affected zone obtained in machining steel XC42 by high-power continuous $\mathrm{CO}_{2}$ laser. Optics and Laser Technology, 40(6): 864-873.

M'hamdi MB, Salem SB, Boujelbene M, and Bayraktar E (2013). Experimental study of the chip morphology in turning hardened AISI D2 steel. Journal of Mechanical Science and Technology, 27(11): 3451-3461. 
Miraoui I, Boujelbene M, and Bayraktar E (2015). Analysis of cut surface quality of sheet metals obtained by Laser machining: Thermal effects. Journal of Advances in Materials and Processing Technologies, 1(3-4): 633-642.

Miraoui I, Boujelbene M, and Zaied M (2016). High-power laser cutting of steel plates: Heat affected zone analysis. Advances in Materials Science and Engineering, 2016: Article ID 1242565, 8 pages. http://dx.doi.org/10.1155/2016/1242565

Miraoui I, Elimi E, Boujelbene M, and Bayraktar E (2013). Analysis of roughness and microstructure for high-power laser cutting of stainless steel. Advanced Science Letters, 19(2): 483-486.

Olabi AG, Casalion G, Benyounis KY, and Rotondo A (2007). Minimization of the residual stress in the heat affected zone by means of numerical methods. Journal of Materials and Design, 28(8): 2295-2302.

Scintilla LD and Tricarico L (2012). Estimating cutting front temperature difference in disk and $\mathrm{CO}_{2}$ laser beam fusion cutting. Optics and Laser Technology, 44(5): 1468-1479.
Shanjin LV and Yang W (2006). An investigation of pulsed laser cutting of titanium alloy sheet. Optics and Laser in Engineering, 44(10): 1067-1077.

Singh H and Garg R (2009). Effects of process parameters on material removal rate in WEDM. Journal of Achievements in Materials and Manufacturing Engineering, 32(1): 70-74.

Uslan I (2005). $\mathrm{CO}_{2}$ laser cutting: Kerf width variation during cutting. Journal of Engineering Manufacture, 219(8): 571-577.

Yilbas BS (2008). Laser cutting of thick sheet metals: effects of cutting parameters on kerf size variations. Journal of Materials Processing Technology, 201(1): 285-290.

Yilbas BS, Akhtar SS, Bayraktar E, Gasem Z (2012). Laser cutting of thin aluminum and silicon alloy: Influence of laser power on kerf. In Advanced Materials Research, 445: 442-447.

Yilbas BS, Arif AFM, Aleem BA (2010). Laser cutting of sharp edge: Thermal Stress analysis. Optics and Lasers in Engineering, 48(1): 10-19. 